\title{
Synthesis and Physical Stability of Novel Au-Ag@SiO Alloy Nanoparticles
}

\author{
Orlando L. Sánchez-Muñoz ${ }^{1,2}$, Jesús Salgado ${ }^{2}$, Juan Martínez-Pastor ${ }^{1}$, Ernesto Jiménez-Villar $^{1,2, *}$ \\ ${ }^{1}$ Instituto de Ciencia de Materiales, Universitat de València. C/ Catedrático José Beltrán No 2, 46980 Paterna Valencia, Spain \\ ${ }^{2}$ Instituto de Ciencia Molecular, Universitat de València. C/ Catedrático José Beltrán No 2, 46980 Paterna Valencia, Spain
}

\begin{abstract}
The present study describes the synthesis of nanoparticles of silver-gold alloys and with their electrokinetic and spectroscopic characterisation. The synthesis was made in two steps. In the first step silver nanoparticles coated with silica $\left(\mathrm{Ag} @ \mathrm{SiO}_{2}\right)$ were synthesised using a novel method assisted by laser ablation. The second step consisted on the introduction of $\mathrm{KAuCl}_{4}$ in the colloidal solution of $\mathrm{Ag} @ \mathrm{SiO}_{2}$ nanoparticles in order to obtain silica-coated silver-gold alloy nanoparticles. The changes of colour and mean diameter of $\mathrm{Ag} @ \mathrm{SiO}_{2}$ nanoparticles caused by the introduction of the gold salt were found dependent on its concentration. Upon increasing $\left[\mathrm{KAuCl}_{4}\right]$ the diameter of nanoparticles diminished and the monodispersity increased. The changes in the interparticle interaction potential as a function of $\left[\mathrm{KAuCl}_{4}\right]$ and time were analysed using $\zeta$-potential values, calculated from their electrophoretic mobilities on the bases of Derjaguin-Laudau-Verwey-Overbeck $\left(\mathrm{DLVO}, U_{T}^{D L V O}\right.$ ) theory. The introduction of $\mathrm{KAuCl}_{4}$ produced a higher stability of the colloid and suggests an increase of the interaction energy barrier. However, as time after synthesis increases the barrier slightly decreases and stabilises at a plateau value. The absorbance measurements (Localised Surface Plasmon Resonance, LSPR) were studied as a function of [KAuCl ${ }_{4}$ ] and time. With increasing $\left[\mathrm{KAuCl}_{4}\right]$ the main absorption band diminishes and red-shifts and a new broad band appears. For each value of $\left[\mathrm{KAuCl}_{4}\right]$, upon increasing time, the two characteristic bands fuse into one and $\lambda_{\max }$ diminishes in a linear fashion. Altogether, these data suggest that the co-reduced solutions of $\mathrm{Ag}^{-}$and $\mathrm{Au}^{3-}$ salts at long time consists of alloy $\mathrm{Ag}-\mathrm{Au}$ nanoparticles, and not a mixture of $\mathrm{Ag}$ and $\mathrm{Au}$ nanoparticles.
\end{abstract}

Keywords Silver-gold nanoparticles, Core-shell nanoparticles, Nanoparticle synthesis, Electrokinetics of nanoparticles, Stability of nanoparticles, $\mathrm{SiO}_{2}$-coated nanoparticles

\section{Introduction}

The synthesis of nanostructured materials with useful and tunable properties is central to the development of nanoscale science and technology. Nanometre scale metal particles exhibit optical, electronic, chemical and magnetic properties of great technological and intellectual value. ${ }^{1}$ Among them, silver and gold nanoparticles (NP) show strong adsorption bands (Localised Surface Plasmon Resonance, LSPR) in the visible region which are absent for the individual atoms as well as in the bulk.,3 The frequency of the LSPR is strongly dependent on different properties of the NP. ${ }^{4-8}$ In turn, the optical and electrokinetic properties of metal NP are strongly influenced by their composition, size, shape, and surrounding environment, such as the proximity of other particles. The assembly of metallic NP presents interesting applications like single molecule detection using surface-enhanced Raman scattering (SERS) $)^{5,12-29}$ and nanoscale optical devices. ${ }^{30,31}$ On the other hand, the presence of a silica layer

* Corresponding authors:

Ernesto.Jimenez@uv.es (Ernesto Jiménez-Villar)

Published online at http://journal.sapub.org/nn

Copyright (C) 2012 Scientific \& Academic Publishing. All Rights Reserved covering metal NP is important ${ }^{9,10}$ because it will separate the metal nano-spheres, avoiding touch with one another, and can also make metal particles more stable in air. More importantly, an outer silica coating provides an opportunity to tailor the electronic and/or optical properties of NP, to obtain 3D metallodielectric structures with a variety of enhanced functionalities. ${ }^{11}$

The interesting colours observed in colloidal solutions of noble metals have led to extensive studies of their spectroscopic properties, in an effort to correlate their behaviour under different micro-environmental conditions. ${ }^{32-47}$ In this sense, $\mathrm{Ag}$ and $\mathrm{Ag}-\mathrm{Au}$ alloy NP are particularly exciting and recent investigations report new modes of preparation ${ }^{48-50}$ and characterisation of their stability, morphology, size, composition and possible applications in nanoscience and nanotechnology.

Silica-coated silver NP $\left(\mathrm{Ag} @ \mathrm{SiO}_{2}\right)$ produced by a method assisted with laser ablation (ALA) are structured by a silver core and a porous silica shell, ${ }^{49-52}$ which in turn consists of the accumulation of small $\mathrm{SiO}_{2}$ nanoparticles $(1-2 \mathrm{~nm}){ }^{49,50}$ In this paper we describe the synthesis and optical properties of alloy Au-Ag@ $@ \mathrm{SiO}_{2}$ NP. The stability of the NP suspensions is also analysed within the framework of the Derjaguin-Laudau-Verwey-Overbeck (DLVO) theory. 


\section{Experimental Section}

Materials. The reagents used were $\mathrm{AgNO}_{3}$ (silver nitrate) 99\%, from Paureac; $\mathrm{KAuCl}_{4}$ (potassium tetrachloroaurate (III) $98 \%$, from Sigma-Aldrich and $\mathrm{Na}_{2} \mathrm{CO}_{3}$ (sodium carbonate) $99 \%$, from Fluka. All these chemicals were used as received without further purification or treatments and their solutions were prepared in de-ionized milliQ water.

Synthesis Procedure. Step 1: Nearly monodispersed $\mathrm{Ag} @ \mathrm{SiO}_{2}$ nanoparticles were produced by the ALA method, using a third-harmonic $(355 \mathrm{~nm})$ Q-Switch Nd:YAG laser irradiation and a Silicon target in an aqueous solution of $\mathrm{AgNO}_{3} 1.25 \times 10^{-4} \mathrm{M}^{48-50}$ ALA is a simple method for the fast (2 to $3 \mathrm{~min}$ ), scalable synthesis of inert colloidal metalsilica nanoparticles in stable colloids. The method is based on the laser ablation of a solid target submerged in an aqueous solution of the metal salts, whose reduction gives rise to nanoparticles. In addition, ablation parameters, target materials and metal salts can be combined and controlled to influence the size, morphology and composition of nanoparticles. ${ }^{48-50}$ Freshly synthesised $\mathrm{Ag} @ \mathrm{SiO}_{2}$ nanoparticles were filtered to eliminate bigger particles, using a NALGENE ${ }^{\circledR}$ filter with a Polietersulfona (PES) membrane and $0.2 \mu \mathrm{m}$ pore size.

Step 2: $8 \mathrm{~mL}$ of $\mathrm{Ag} @ \mathrm{SiO}_{2}$ nanoparticle suspension were distributed in 6 vials and each of them added a particular amount of $\mathrm{KAuCl}_{4}$, reaching final concentrations from $0.1 \times 10^{-4}$ to $0.2 \times 10^{-4} \mathrm{M}$. This procedure was carried out under continuous agitation of the sample and with slow additions of $\mathrm{KAuCl}_{4}$ (in steps of $0.02 \times 10 \mathrm{M}$ increments).

Step 3: About five hours after addition of the gold salt, $\mathrm{Na}_{2} \mathrm{CO}_{3}$ was was added to reach a $0.5 \mathrm{mM}$ concentration, in order to get $\mathrm{pH}$ stabilisation at $\sim 8.5$. The electrokinetic and spectroscopic characterisation for $\mathrm{Ag} @ \mathrm{SiO}_{2}$ and $\mathrm{Au}-$ $\mathrm{Ag} @ \mathrm{SiO}_{2}$ alloy nanoparticles were then performed by measuring the absorbance, size and $\zeta$-potential as a function of time (after NP synthesis) and for each of the different $\mathrm{KAuCl}_{4}$ concentrations employed in step 2 .

Measurements of NP diameter. Small aliquots of each sample were transferred onto copper mesh grids, covered with a carbon film and let dry on air. A transmission electron microscope (JEOL, mod. JEM-1010, $100 \mathrm{kV}$ accelerating voltage) with a digital MegaView III camera and "Analysis" software for image acquisition, was employed to take electron micrographs of the resultant $\mathrm{Ag} @ \mathrm{SiO}_{2}$ and $\mathrm{Au}-$ $\mathrm{Ag} @ \mathrm{SiO}_{2}$ alloy NP. From these electron micrographs the diameter of NP was measured using the Image J $1.40 \mathrm{~g}$ software (National Institute of Health, USA).

Spectroscopic Measurements. NP-sample solutions were transferred into $10 \mathrm{~mm}$ quartz cells and their absorption spectra were recorded using a UV-VIS Spectrophotometer (UV-250 1PC) from Shimadzu Corporation, Japan.

Electrophoretic Mobility Measurements. The ZetaSizer NanoZS Zen3600 (Malvern Instruments Ltd., UK) was used to measure the electrophoretic mobilities $\left(\mu_{\mathrm{e}}\right)$ of each nanoparticle sample. NanoZS employs back scattering data detection $\left(173^{\circ}\right.$ scattering angle) with a $4 \mathrm{~mW}$ He-Ne laser
$(633 \mathrm{~nm})$. The electrophoretic mobilities were acquired using the M3-PALS technique, with a folded capillary cell (DTS1060). The $\zeta$-potential values were calculated from the electrophoretic mobilities using the Henry's approximation. Three measurements of each NP sample were made at $25 \pm$ $0.1^{\circ} \mathrm{C}$ to get average values.

\section{Results and Discussion}

Pure $\mathrm{Ag} @ \mathrm{SiO}_{2}$ solutions are typically of a pale yellow colour (Figure 1 top, sample 1). This does not change in presence of $\mathrm{Na}_{2} \mathrm{CO}_{3} \mathrm{pH}$ 8-8.5 (Figure 1 top, sample 1a). However, upon addition of $\mathrm{KAuCl}_{4}$ the colour changes gradually depending on the concentration of the gold salt and finally acquires a yellowish-red colour at the highest $\mathrm{KAuCl}_{4}$ concentration used $(0.2 \times 10 \mathrm{M}$, Figure 1 top, samples 2-7). We interpret these changes as being due to gold reduction and concomitant oxidation of silver from the NP core, leading to the formation of $\mathrm{Au}-\mathrm{Ag} @ \mathrm{SiO}_{2}$ alloy NP (see below).

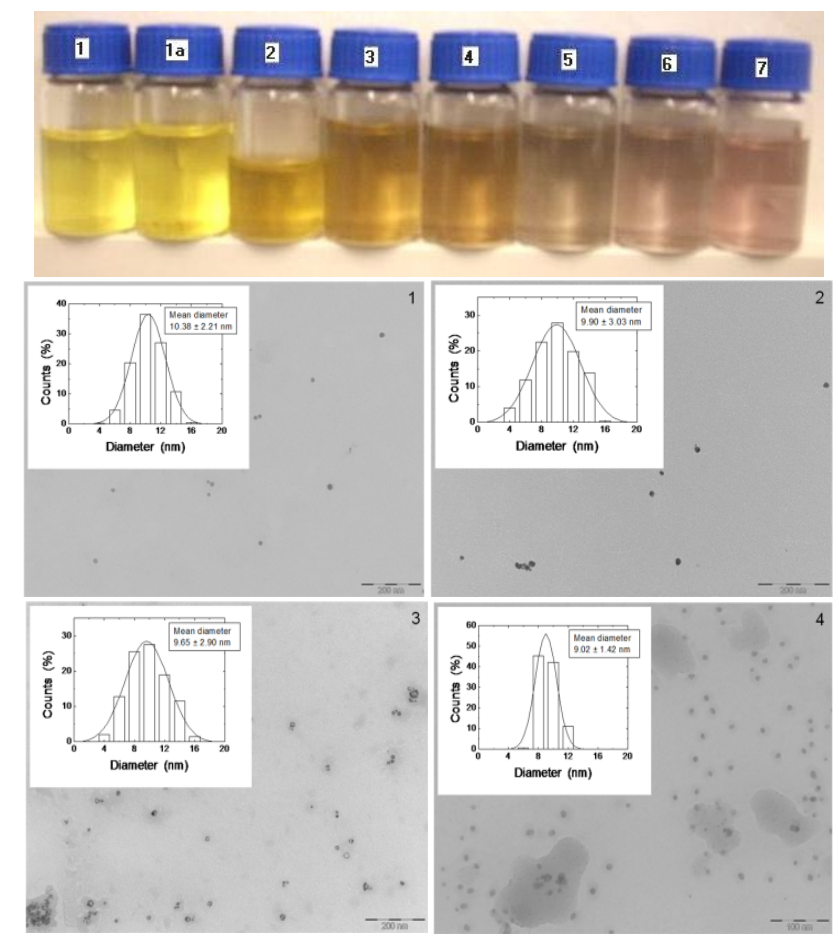

Figure 1. Top, pictures of aqueous suspensions of $\mathrm{Ag} @ \mathrm{SiO}_{2}$ nanoparticles. Sample 1, immediately after preparation using the ALA method. To this sample $\mathrm{Na}_{2} \mathrm{CO}_{3} 0.5 \mathrm{mM}$ was added $\sim 5$ hours after synthesis (sample la) and it was distributed into samples 2-7, to which the following concentrations of $\mathrm{KAuCl}_{4}$ were added: Sample 2, $0.1 \times 10^{-4} \mathrm{M}$; sample $30.12 \times 10^{-4} \mathrm{M}$;

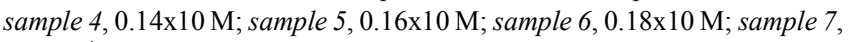
$0.2 \times 10^{-4} \mathrm{M}$. Middle and bottom, TEM images of aliquots from samples 1-4. The insets show the nanoscale size distribution of particles.

TEM images show nearly monodisperse suspensions of NP for all samples. The histograms of their diameter provide their size distribution. The mean diameter decreases from 10.38 to $9.02 \mathrm{~nm}$ upon increasing $\left[\mathrm{KAuCl}_{4}\right]$ in the preparation procedure, with the monodispersity being more accentuated for the sample with highest $\left[\mathrm{KAuCl}_{4}\right]$. The decrease in 
size should be a consequence of the chemical reactions that take place between the $\mathrm{Ag} @ \mathrm{SiO}_{2} \mathrm{NP}$ and $\mathrm{KAuCl}_{4}$, namely reduction of $\mathrm{Au}^{3}$ to $\mathrm{Au}$ and oxidation of $\mathrm{Ag}$ to $\mathrm{Ag}$. This should eliminate three $\mathrm{Ag}$ ions for each $\mathrm{Au}^{3}$ incorporated in the NP metal core, in agreement with a smaller size of $\mathrm{Au}-\mathrm{Ag} @ \mathrm{SiO}_{2}$ NP. On the other hand, for larger NP, the surface charge should be higher, which induces a higher concentration of ions in the vicinity of NP and is expected to increase their chemical reactivity. Then, because the larger particles are expected to react more than the smaller NP, the formation of Au-Ag@ $@ \mathrm{SiO}_{2}$ should also decrease the width of the size distribution (increase monodispersity), as observed.

Physical stability of the Au-Ag@ $\mathrm{SiO}_{2}$ alloy nanoparticles. The study of the physical stability of NP suspensions was based on $\zeta$-potential measurements and their interpretation using the classical DLVO theory. Such a theoretical framework has been employed in colloid science to study particle-particle interactions, coagulation, sedimentation, filtration and the behaviour of electrolyte solutions. ${ }^{53-56}$ This theory is based on the idea that pair-wise interactions arise from the interplay of attractive van der Waals forces $\left(\mathrm{F}_{\text {attr }}\right)$ and repulsive Coulomb forces $\left(\mathrm{F}_{\text {rep }}\right)$ screened by Debye-Hückel ion clouds. Then, the dispersed colloid will be stable (non aggregated) for $F_{\text {rep }}>>F_{\text {attr }}$ and the total interaction potential between two nanoparticles $\left(U_{T}^{D L V O}\right)$ can be expressed as the sum of electrostatic repulsion $\left(\mathrm{U}_{\text {elec }}\right)$ and the van der Waals attraction $\left(\mathrm{U}_{\mathrm{vdw}}\right)::^{53,54}$

$$
\mathrm{U}_{\mathrm{T}}^{\mathrm{D}} \quad{ }^{\mathrm{L}}={ }^{\mathrm{V}} \mathrm{U}_{1}^{\mathrm{O}}\left(\mathrm{e}^{\mathrm{l}+}\right) \mathrm{U}_{\mathrm{d}}\left(\mathrm{C}_{\mathrm{w}}\right.
$$

Depending on the particle size and the thickness of the double layer, the electrostatic repulsion potential $\left(\mathrm{U}_{\text {elec }}\right)$ between two colloidal particles of radii $a$ (in general $a_{l}$ and $a_{2}$ ) can be expressed as: 55

$$
\mathrm{U}_{\mathrm{e}} \quad\left({ }_{1}=\mathrm{e} \mathrm{2} \pi \varepsilon_{0} \varepsilon_{\mathrm{r}}\left(+\mathbb{A} \psi_{\mathrm{o}}^{2} \mathrm{e}\right)[-\mathbf{K}(-2 \mathrm{p} \mathrm{d}]\right.
$$

where $\varepsilon_{\mathrm{r}}$ is the permittivity of the medium, $\psi_{\mathrm{o}}$ is the potential at the particle surface, which can be estimated from the $\zeta$-potential measurements, ${ }^{57-61} \kappa$ is the inverse Debye length and $\Delta$ is the thickness of the Stern layer.

Assuming that the particles are spherical and that the surface potential and the background ionic strength are constant, the van der Waals attraction potential $\left(\mathrm{U}_{\mathrm{vdw}}\right)$ between the two particles can be calculated as: ${ }^{54-56,58}$

$$
U_{v} \quad\left(_{d}=r_{w} \frac{A}{6}\left[\frac{2^{2}}{r^{2}-4^{2}}+\frac{\mathrm{a} 2^{2}}{a^{2}}+1^{a} \frac{r^{2}-4^{2}}{r^{2}}\right]\right.
$$

where $r$ is the distance between two particles $(r=h+2 a$, with $h$ being the distance between the approaching surfaces).$^{62}$ The van der Waals interaction is the dominant at- traction. It is dependent on the particle radii $a$, the separation distance $h$ and the Hamaker constant $A$, which plays an important role in the description of attraction energy between the particles. ${ }^{63}$

In order to calculate the electrostatic repulsion potential $\left(\mathrm{U}_{\text {elec }}\right)$ of NP, we first study of their $\zeta$-potentials through measurements of electrophoretic mobility. For that we used Henry's approximation, where $f(\kappa a)$ was calculated for $\kappa a \leq$ $1 .{ }^{64}$ Such an analysis was performed for the $\mathrm{Ag} @ \mathrm{SiO}_{2} \mathrm{NP}$ immediately after their synthesis (sample 1), as well as after addition of $\mathrm{KAuCl}_{4}$ at the required concentrations (samples 2-4).

The changes of the $\zeta$-potential of each sample are represented in Figure 2. The electrophoretic mobility increases (in absolute value) with $\left[\mathrm{KAuCl}_{4}\right]$, from $2.34 \times 10^{-8} \mathrm{~m}^{2} \mathrm{~V}^{-1} \mathrm{~s}^{-1}$ (sample 1) to $3.40 \times 10^{-8} \mathrm{~m}^{2} \mathrm{~V}^{-1} \mathrm{~s}^{-1}$ (sample 2) and $3.64 \times 10^{-8}$ $\mathrm{m}^{2} \mathrm{~V}^{-1} \mathrm{~s}^{-1}$ (sample 3). For sample 4, the increment of the electrophoretic mobility was smaller $\left(3.35 \times 10^{-8} \mathrm{~m}^{2} \mathrm{~V}^{-1} \mathrm{~s}^{-1}\right)$.

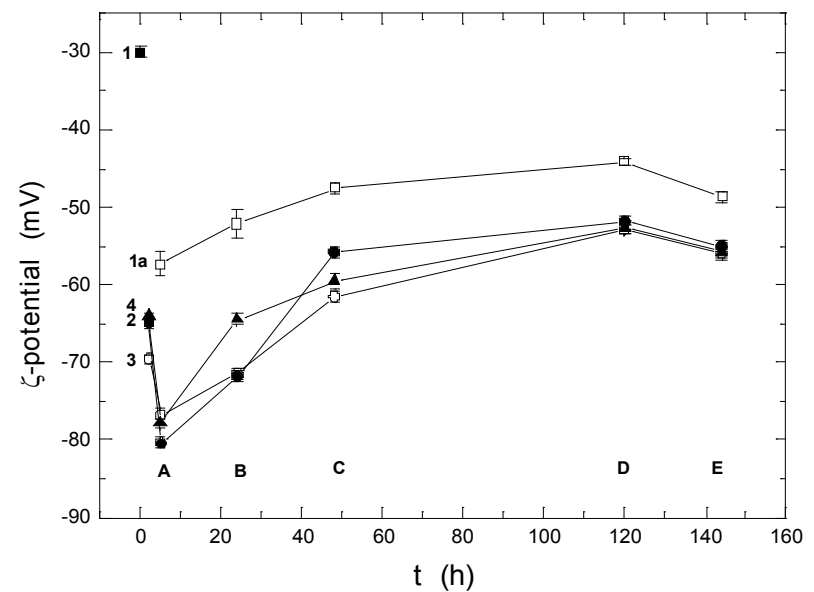

Figure 2. $\zeta$-potential of $\mathrm{Ag} @ \mathrm{SiO}_{2}$ (1, 1a) and Au-Ag@ $@ \mathrm{SiO}_{2}$-alloy NP (2-4) as a function of time (A-5 hours; B-24 hours; C-48 hours; D-120 hours; E-144 hours). The plotted standard error was calculated from the errors of experimental measures of electrophoretic mobilities.

Interestingly, the addition of $\mathrm{Na}_{2} \mathrm{CO}_{3} 0.5 \mathrm{mM}$ to $\mathrm{Ag} @ \mathrm{SiO}_{2}$ $\mathrm{NP}, 5$ hours after synthesis (sample 1a) and Au-Ag@ $@ \mathrm{SiO}_{2}$ alloy NP (samples 2-4), provokes an additional increase in the electrophoretic mobility, again being larger for sample Ia $\left(3 \times 10^{-8} \mathrm{~m}^{2} \mathrm{~V}^{-1} \mathrm{~s}^{-1}\right)$ than for samples 2-4 $(4.21,4.02$ and $4.07 \times 10^{-8} \mathrm{~m}^{2} \mathrm{~V}^{-1} \mathrm{~s}^{-1}$, respectively). This effect could be a consequence of a higher accumulation of silica on the surface of nanoparticles and/or $\mathrm{pH}$ increase from 5 to $8.5{ }^{65,66}$ After 24, 48, 120 and 144 hours the electrophoretic mobility continues increasing, reaching a plateau at approximately the same value for samples 2-4.

Table 1. Input parameters used for DLVO calculations and analysis of stability of NP suspensions.

\begin{tabular}{|ccccccc|}
\hline Sample & ionic strength $[\mathbf{m M}]$ & $\mathbf{\kappa} \mathbf{1 0}^{\mathbf{8}}\left[\mathbf{m}^{-\mathbf{1}}\right]$ & $\mathbf{a}[\mathbf{n m}]$ & $\mathbf{K a}$ & $\mathbf{\Delta}^{*}\left[\mathbf{A}^{\circ} \mathbf{]}\right.$ & $\mathbf{A}^{* \pi} \mathbf{1 0}^{-21}[\mathbf{J}]$ \\
\hline 2 & 0.5 & 2.39 & 4.95 & 1.0058 & 4.63 & 8.49 \\
\hline 3 & 0.5 & 2.39 & 4.83 & 1.0053 & 4.63 & 8.49 \\
\hline 4 & 0.5 & 2.39 & 4.51 & 1.0042 & 4.63 & 8.49 \\
\hline
\end{tabular}

${ }^{*}$ The thickness of Stern layer was taken as the diameter of the hydration sphere of $\mathrm{CO}_{3}{ }^{2-}$ ions.

"** The Hamaker constant used was that corresponding to fused silica. ${ }^{67}$ 
The values of $\zeta$-potential are used to estimate the electrokinetic properties and colloidal stability of the NP suspensions. The interaction potentials between two particles can be calculated as a function of their separation from Eqs. $1-3$.

The changes in the interaction potential of the $\mathrm{Au}-\mathrm{Ag} @ \mathrm{SiO}_{2}$ alloy NP as a function of time are shown in Figure 3. Before addition of $\mathrm{KAuCl}_{4}$ (samples 1 and $1 a$ ), the $\mathrm{Ag} @ \mathrm{SiO}_{2} \mathrm{NP}$ are stable since the energy barrier is high enough to prevent aggregation. From the previous measurements we have inferred that the introduction of $\mathrm{Au}^{3+}$ in the solution is followed by incorporation of gold to the nanoparticles, likely accompanied by partial oxidation of silver:
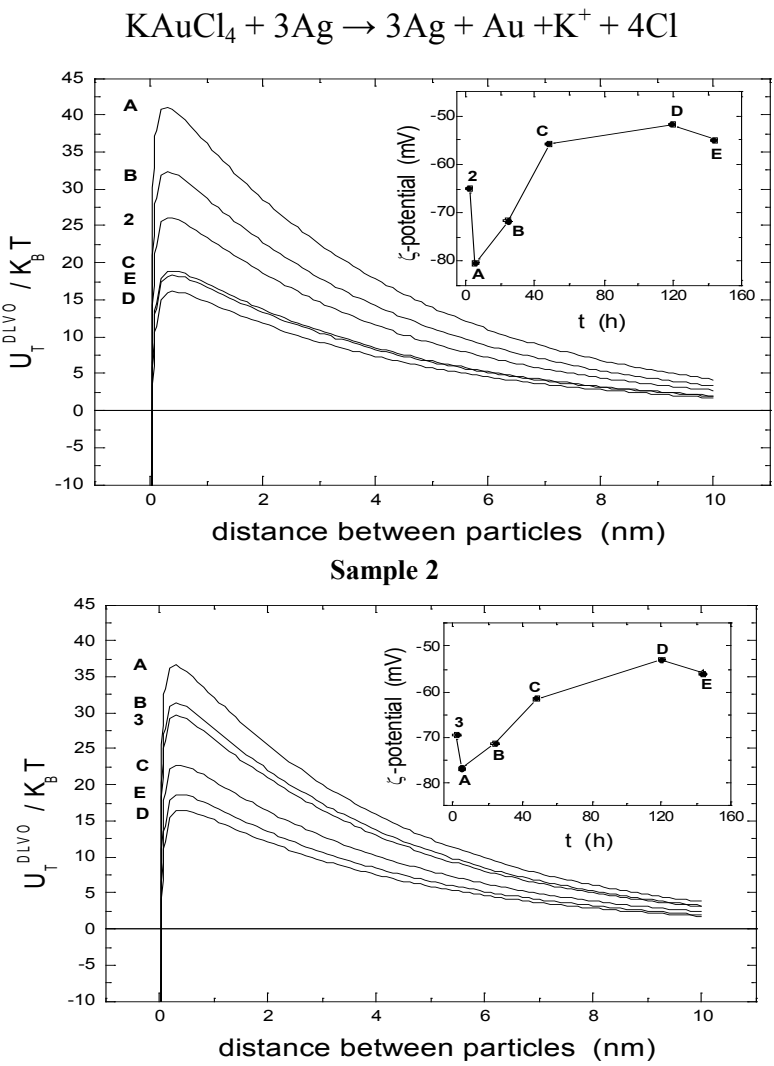

Sample 3

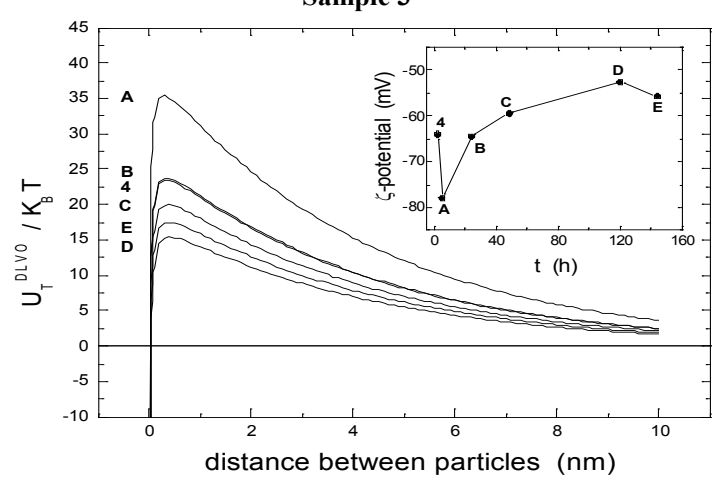

Sample 4

Figure 3. Changes in the inter-particle interaction potential (net energy barrier $U_{T}^{D L V O}$ ) for Au-Ag@ $\mathrm{SiO}_{2}$ alloy nanoparticles, samples 2, 3 and 4, as a function of time (A-5 hours plus addition of $\mathrm{Na}_{2} \mathrm{CO}_{3}, \mathrm{~B}-24$ hours, C-48 hours, D-120 hours, E-144 hours). The inset shows the $\zeta$-potential changes as in Figure 2.
This could originate a fine layer of $\mathrm{Au}$ on the surface of $\mathrm{Ag}$ nanoparticles. In parallel, the diameter of the metallic core of the nanoparticles diminishes, due to reduction of $\mathrm{Ag}$, and the thickness of the silica layer could increase. Additionally, it is known that nanoparticles of gold and silver alloys present a higher electron density on their surface than nanoparticles of $\mathrm{Au}$ or Ag separately. This fact is responsible of an increment of the catalytic activity of bimetallic Au-Ag nanoparticles, specially when $\mathrm{Au}$ is mainly located near the surface. ${ }^{68-70}$ Therefore, the incorporation of Au to NP is in agreement with the observed increment in the module of the $\zeta$-potential. With time, the Au atoms that conform the surface layer could spread toward the interior of the NP, creating a radial distribution with a more homogeneous composition. This effect, in turn, would tend to diminish the $\zeta$-potential, to be stabilized at a given value, as we observe.

After 5 hour and addition of $\mathrm{Na}_{2} \mathrm{CO}_{3}$, the energy barrier increases significantly for all samples. Such an increase tends to be similar for all samples after longer times, reaching approximately the same value of $U_{T}^{D L V O}$.

Optical properties of the Au-Ag@SiO ${ }_{2}$ alloy nanoparticles in $\mathrm{Na}_{2} \mathrm{CO}_{3}$ Solution. The absorbance of $\mathrm{Ag} @ \mathrm{SiO}_{2}$ and $\mathrm{Au}-\mathrm{Ag} @ \mathrm{SiO}_{2}$ alloy NP as a function of time is given in Figure 4. $\mathrm{Ag} @ \mathrm{SiO}_{2} \mathrm{NP}$ show a characteristic peak at $\sim 403$ $\mathrm{nm}$ (Figure 4, top, inset). The addition of $\mathrm{Na}_{2} \mathrm{CO}_{3}$ provokes a red shift of $\lambda_{\max }$ which may be due to a higher accumulation of silica on the surface of NP which, as we have suggested above. $^{71,72}$
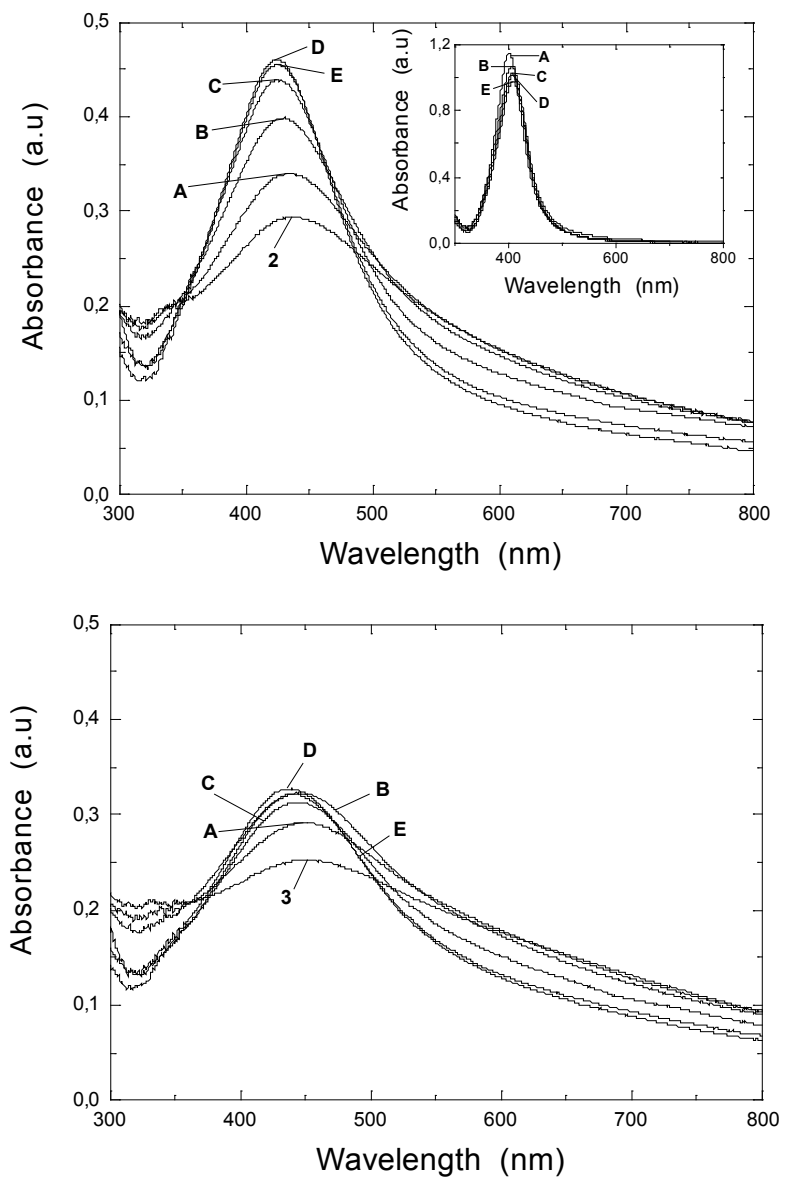


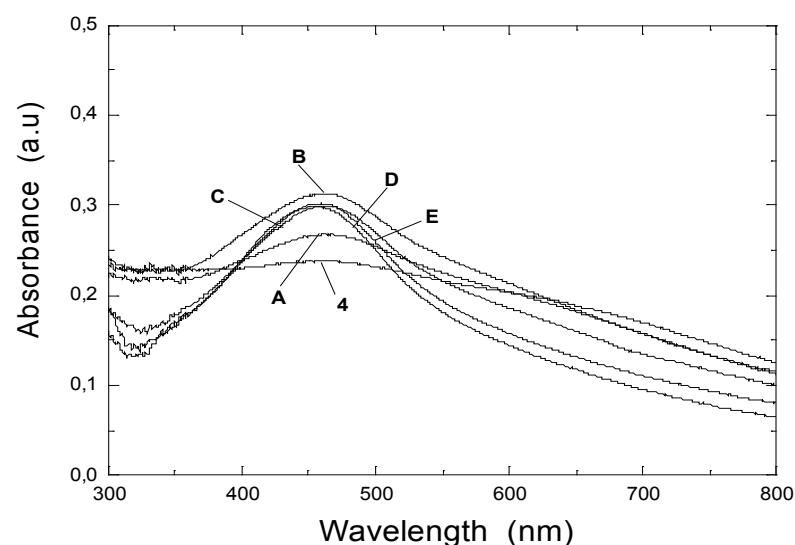

Figure 4. UV-VIS absorption spectra for $\mathrm{Au}-\mathrm{Ag} @ \mathrm{SiO}_{2}$ alloy nanoparticles as a function of the time (A-5 hours; B-24 hours; C-48 hours; D-120 hours; E-144 hours). The inset shows the UV-VIS absorption spectra of the $\mathrm{Ag} @ \mathrm{SiO}_{2}$ nanoparticles.

At increasing concentrations of $\mathrm{KAuCl}_{4}$ the main absorption band typical of Ag-core NP diminishes and shifts toward the red. In parallel, a new broad absorption band appears at larger wavelengths. This second band can be attributed to a layer of Au on the surface of the NP. ${ }^{73-79}$ Therefore, from the absorption spectra we infer that in presence of $\mathrm{KAuCl}_{4}$ an $\mathrm{Au}$-shell is formed over the $\mathrm{Ag} @ \mathrm{SO}_{2} \mathrm{NP}$, suggesting that the co-reduced solution consists of alloy Au-Ag@ $\mathrm{SiO}_{2}$ nanoparticles and not a mixture of $\mathrm{Ag} @ \mathrm{SiO} 2$ and $\mathrm{Au}$ NP.

As time passes after synthesis, the initial shifts of $\lambda_{\max }$ of $\mathrm{Au}-\mathrm{Ag} @ \mathrm{SiO}_{2} \mathrm{NP}$ diminish as follows: sample 2, 434.0-424.5 nm; sample 3, 450.5-442.0 nm and sample 4, $465.0-458.5 \mathrm{~nm}$. In parallel, the intensity of the principal absorption band increases, while the secondary broad band decreases up to a point where it cannot be observed. This time effects can be explained by the diffusion of Au from an initial external layer into the Ag core of the NP.

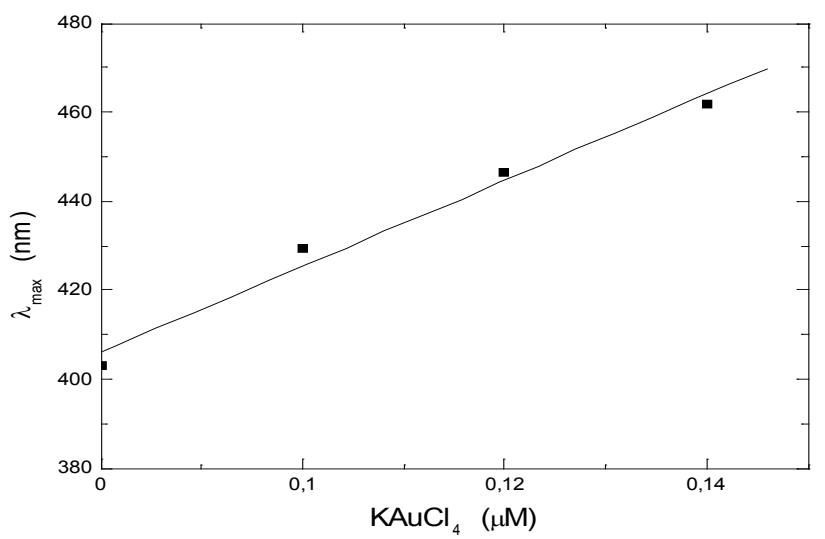

Figure 5. Maximum absorbance wavelength as a function of $\left[\mathrm{KauCl}_{4}\right]$, corresponding to data in the Figure 4.

$\lambda_{\max }$ increases in a linear fashion with [ $\left.\mathrm{KAuCl}_{4}\right]$ (Figure 5, 144 hours after addition). It has been found that the value of $\lambda_{\max }$ in $\mathrm{Au}-\mathrm{Ag}$ alloy NP is related to the $\mathrm{Au} / \mathrm{Ag}$ ratio. Thus, using $\lambda_{\max }$ obtained for each sample we can estimate the approximated Au concentration in the nanoparticles. For the samples 2, 3 and 4 , with $\lambda_{\max }=424.5,442.0$ and $458.5 \mathrm{~nm}$, respectively, the corresponding $\mathrm{Au} / \mathrm{Ag}$ ratios are estimated to be $20 / 80,30 / 70$ and $45 / 55$ respectively. ${ }^{80,81}$ However, according to the amount of gold added to each sample and assuming that each $\mathrm{Au}^{3+}$ ion replaces three silver atoms in the NP, the $\mathrm{Au} / \mathrm{Ag}$ ratios should rather be 10/90, 12/88 and $14 / 86$, respectively. This again indicates that the Au atoms are not distributed homogeneously in the nanoparticle, but localized mainly in a gold-rich shell.

In Summary, upon addition of $\mathrm{KAuCl}_{4}$ to the colloidal solution of $\mathrm{Ag} @ \mathrm{SiO}_{2}$, the $\mathrm{Au}^{3+}$ ions appear to react with the silver core of the nanoparticle, oxidizing the $\mathrm{Ag}$ to $\mathrm{Ag}$. This would structure an $\mathrm{Au}$ shell on the nanoparticle which is schematized in Figure 6. The appearance of a broad absorption band displaced toward the red (Figure 4), which is characteristic of $\mathrm{Au}$ shell, is in agreement with that interpretation.

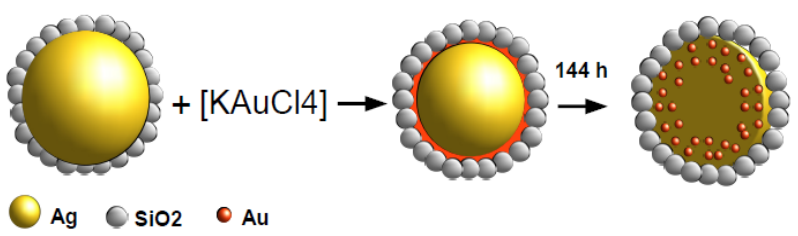

Figure 6. Schematic representation of the synthesis and structure of $\mathrm{Au}-\mathrm{Ag} @ \mathrm{SiO}_{2}$ alloy nanoparticles

With the time (144 hours after addition of the gold salt) the $\mathrm{Au}$ atoms that conform the initial shell appear to have spread toward the interior of the NP, although still predominating on the external atomic monolayers of the nanoparticle. In other words, these nanoparticles should be formed by a Ag core or (Ag-Au) with lower concentration of gold atoms and an shell with high Au content (Figure 6).

\section{ACKNOWLEDGEMENTS}

This research was funded by grants as Invited Researcher from the University of Valencia, Spain (OLS) and Juan de la Cierva Program from the Ministry of Science and Innovation, Spain (EJ).

\section{REFERENCES}

[1] Atwater, H. A. Sci. Am. 2007, 296, 56.

[2] Alvarez, M. M.; Khoury, J. T.; Schaaff, T. G.; Shafigullin, M. N.; Vezmar, I.; Whetten, R. L. J. Phys. Chem. B 1997, 101, 3706-3712.

[3] Link, S.; El-Sayed, M. A. J. Phys. Chem. B 1999, 103, 8410-8426.

[4] Efrima, S.; Metiu, H. J. Chem. Phys. 1979, 70, 1602-1613.

[5] Aravind, P. K.; Metiu, H. Chem. Phys. Lett. 1980, 74, 301-305.

[6] Gersten, J.; Nitzan, A. J. Chem. Phys. 1980, 73, 3023-3037.

[7] Wang, D.; Chew, H.; Kerker, M. Appl. Opt. 1980, 19, 
2256-2257.

[8] Rampi, M. A.; Schueller, O. J. A.; Whitesides, G. M. Appl. Phys. Lett. 1998, 72, 1781-1783.

[9] Graf, C.; van Blaaderen, A. Langmuir. 2002, 18 (2), 524-534.

[10] Graf, C.; Vossen, D.; Imhof, A.; van Blaaderen, A. Langmuir 2003, 19 (17), 6693-6700.

[11] Tullman, J. A.; Finney, W.; Lin, Y.; Bishonoi, S. Plasmonic. 2007, 2 (3), 119-127.

[12] Jeanmaire, D. L.; Van Duyne, R. P. J. Electroanal. Chem. 1977, 84, 1-20.

[13] Albrecht, M. G.; Creighton, J. A. J. Am. Chem. Soc. 1977, 99, 5215-5217.

[14] Moskovits, M. J. Chem. Phys. 1978, 69, 4159-4161.

[15] (Moskovits, M. Solid State Commun. 1979, 32, 59-62.

[16] (Pettinger, B.; Tadjeddine, A.; Kolb, D. M. Chemical Physics Letters 1979, 66, 544-548.

[17] (Otto, A. Applied Surface Science 1980, 6, 309-355.

[18] Otto, A. Surf. Sci. 1980, 101, 99-108.

[19] Dornhaus, R.; Benner, R. E.; Chang, R. K.; Chabay, I. Surf. Sci. 1980, 101, 367-373.

[20] Chen, C. Y.; Burstein, E. Phys. Rev. Lett. 1980, 45, 1287.

[21] Chang, R. K.; Furtak, T. E. En Surface Enhanced Raman Scattering; New York, 1982; 35.

[22] Shen, Y. R. The Principles of Nonlinear Optics; Wiley: New York, 1984.

[23] Xu, H.; Bjerneld, E. J.; Kall, M.; Borjesson, L. Phys. Rev. Lett. 1999, 83, 4357.

[24] Hulteen, J. C.; Van Duyne, R. P. J. Vac. Sci. Technol. A 1995, $13,1553-1558$.

[25] Adrian, F. J. Chem. Phys. Lett. 1981, 78, 45-49.

[26] Wang, D. -.; Kerker, M. Phys. Rev. B 1981, 24, 1777.

[27] Schatz, G. C. Acc. Chem. Res. 1984, 17, 370-376.

[28] Kerker, M. Acc. Chem. Res. 1984, 17, 271-277.

[29] Knoll, B.; Keilmann, F. Nature 1999, 399, 134-137.

[30] Quinten, M.; Leitner, A.; Krenn, J. R.; Aussenegg, F. R. Opt. Lett. 1998, 23, 1331-1333.

[31] Ricard, D.; Roussignol, P.; Flytzanis, C. Opt. Lett. 1985, 10, 511-513.

[32] Malinsky, M. D.; Kelly, K. L.; Schatz, G. C.; Van Duyne, R. P. J. Am. Chem. Soc. 2001, 123, 1471-1482.

[33] Bain, C. D.; Whitesides, G. M. J. Am. Chem. Soc. 1989, 111, 7164-7175.

[34] Bain, C. D.; Evall, J.; Whitesides, G. M. J. Am. Chem. Soc. 1989, 111, 7155-7164.

[35] Templeton, A. C.; Pietron, J. J.; Murray, R. W.; Mulvaney, P. J. Phys. Chem. B 2000, 104, 564-570.
[36] Thomas, K. G.; Zajicek, J.; Kamat, P. V. Langmuir 2002, 18, 3722-3727.

[37] Zhang, J. Z. Acc. Chem. Res. 1997, 30, 423-429.

[38] Brust, M.; Fink, J.; Bethell, D.; Schiffrin, D. J.; Kiely, C. J. Chem. Soc., Chem. Commun. 1995, 16, 1655-1656.

[39] Brust, M.; Walker, M.; Bethell, D.; Schiffrin, D. J.; Whyman, R. J. Chem. Soc., Chem. Commun. 1994, 7, 801-802.

[40] Sarathy, K. V.; Kulkarni, G. U.; Rao, C. N. R. Chem. Commun. 1997, 6, 537-538.

[41] Nakao, Y. J. Chem. Soc., Chem. Commun. 1994, 18, 2067-2068.

[42] Lin, S. T.; Franklin, M. T.; Klabunde, K. J. Langmuir 1986, 2, 259-260.

[43] Esumi, K.; Kameo, A.; Suzuki, A.; Torigoe, K. Colloids Surf. A 2001, 189, 155-161.

[44] Bohren, C. F.; Huffman, D. R. Absorption and Scattering of Light by Small Particles; Wiley Interscience: New York, 1983.

[45] Cretu, C.; van der Lingen, E. Gold Bulletin. 1999, Quinten, M. J. Clusters Sci. 1999, 10, 319-358.

[46] Ghosh, S. K.; Nath, S.; Kundu, S.; Esumi, K.; Pal, T. J. Phys. Chem. B 2004, 108, 13963-13971.

[47] Jiménez, E.; Abderrafi, K.; Martínez-Pastor, J.; Abargues, R.; Luís Valdés, J.; Ibáñez, R. Superlatices and Microstructures 2008, 43, 487-493.

[48] Jiménez, E.; Abderrafi, K.; Abargues, R.; Valdés, J. L.; Martínez-Pastor, J. P. Langmuir 2010, 26, 7458-7463.

[49] Jimenez, E.; Abderrafi, K.; Abargues, R.; Martinez-Pastor, J.; Valdes, J.; Ibañez, R. Patent Number(s): WO2009030799-A1 Patent Assignee: Univ. Valencia, Spain. 2009.

[50] Fuertes, G.; Sánchez-Muñoz, O. L.; Pedrueza, E.; Abderrafi, K.; Salgado, J.; Jiménez, E. Langmuir. 2011, 27 (6), 2826-2833.

[51] Fuertes, G.; Pedruaza, E.; Abderrafi, K.; Abargues, R.; Sánchez-Muñoz, O.; Martinez-Pastor, J.; Salgado, J.; Jiménez, E. Biomedical Optics and Imaging - Proceeding of SPIE 2011, 8092 , article number $80921 \mathrm{M}$.

[52] Yang, W.; Schatz, G. C.; Van Duyne, R. P. J. Chem. Phys. 1995, 103, 869-875.

[53] Wang, T.; Zhang, D.; Xu, W.; Li, S.; Zhu, D. Langmuir 2002, $18,8655-8659$.

[54] Hunter, R. J. Foundation of Colloid Science; Clarendom Press: Oxford, U.K., 1992.

[55] Verwey, E. J.; Overbeek, J. Th. G. Theory of the Stability of Lyophobic Colloids; Dover Mineloa: New York, 2000.

[56] Hamaker, H. C. Rec. Trav. Chim. 1936, 55, 1015-1026.

[57] Hamaker, H. Rec. Tranv. Chim. 1937, 56, 727-747.

[58] Matijević, E.; Mathai, K. G.; Ottewill, R. H.; Kerker, M. J. Phys. Chem. 1961, 65, 826-830. 
[59] Vincent, B.; Bijsterbosch, B. H.; Lyklema, J. J. Colloid Interface Sci. 1971, 37, 171-178.

[60] Bastos, D.; Nieves, F. J. J. Colloid \& Polymer Sci. 1994, 272, 592-597.

[61] Lyklema, J. Fundamentals of Interface and Colloid Science: Fundamentals; Academic Press: U.S.A, 1995; Vol. I.

[62] Lee, T. G.; Kim, K.; Kim, M. S. J. Raman Spectrosc. 1991, 22 , 339-344.

[63] Ohshima, H. J. Colloid and Interface Science 1994, 168, 269-271.

[64] Dougherty, G. M.; Rose, K. A.; Tok, J. B.; Pannu, S. S.; Chuang, F. Y. S.; Sha, M. Y.; Chakarova, G.; Penn, S. G. Electrophoresis 2008, 29, 1131-1139.

[65] Alvarez-Puebla, R. A.; Arceo, E.; Goulet, P. J. G.; Garrido, J. J.; Aroca, R. F. J. Phys. Chem. B 2005, 109, 3787-3792.

[66] Hunter, R. J. En Foundations of Colloid Science; Oxford University Press: U.K, 2001; pág. 572.

[67] Tokonami, S.; Morita, N.; Takasaki, K.; Toshima, N. J. Phys. Chem. C. 2010, 114, 10336-10341.

[68] Ishida, T.; Kinoshita, N.; Okatsu, H.; Akita, T.; Takei, T.; Haruta, M. Angew. Chem. Int. Ed. 2008, 47, 9265.

[69] Pina, C. D.; Falleta, E.; Prati, L.; Rossi, M. Chem. Soc. Rev. 2008, 37, 2077.
[70] Mulvaney, P.; Underwood, S. Langmuir 1994, 10, 3427.

[71] Ung, T.; Liz-Marzán, L. M.; Mulvaney, P. Langmuir 1998, 14, 3740 .

[72] Srnova-Sloufova, I.; Lednicky, F.; Gemperle, A.; Gemperlova, J. Langmuir 2000, 16, 9928-9935.

[73] Ah, C. S.; Hong, S. D.; Jang, D. J. Phys. Chem. B 2001, 105, 7871-7873.

[74] Rivas, L.; Sanchez-Cortes, S.; Garcia-Ramos, J. V.; Morcillo, G. Langmuir 2000, 16, 9722-9728.

[75] Mallik, K.; Mandal, M.; Pradhan, N.; Pal, T. Nano Lett. 2001, 1, 319-322.

[76] Lu, L.; Wang, H.; Zhou, Y.; Xi, S.; Zhang, H.; Hu, J.; Zhao, B. Chem. Commun. 2002, 2, 144-145.

[77] Kelly, K. L.; Jensen, T. R.; Lazarides, A. A.; Schatz, G. C. En Metal Nanopartilces: Synthesis, Characterization and Applications; Marcel Dekker: New York, 2002.

[78] Mulvaney, P.; Giersing, M.; Henglein, A. J. Phys. Chem. 1993, 97, 7061-7064.

[79] Zhang, Q. B.; Xie, J. P.; Liang, J.; Lee, J. Y. Advanced Functional Materials. 2009, 19 (9), 1387-1398.

[80] Mallin, M. P.; Murphy, C. J. Nano Letters. 2002, 2 (11), 1235-1237 